\title{
2D-DIGE analysis of phospho-enriched fractions from dasatinib-treated melanoma cell lines
}

\author{
Alex J. Eustace ${ }^{a, *, 1}$, Paul Dowling ${ }^{a, 1}$, Michael Henry ${ }^{a}$, Padraig Doolan $^{a}$, Paula Meleady ${ }^{a}$, \\ Martin Clynes ${ }^{a}$, John Crown ${ }^{a, b}$, Norma O'Donovan ${ }^{a}$ \\ ${ }^{a}$ National Institute for Cellular Biotechnology, Dublin City University, Dublin 9, Ireland \\ bepartment of Medical Oncology, St. Vincent's University Hospital, Dublin 4, Ireland
}

\section{A R T I C L E I N F O}

\section{Article history:}

Received 5 October 2010

Accepted 29 December 2010

Available oline 13 January 2011

Keywords:

2D-DIGE

Phosphoproteomics

Dasatinib

Melanoma

Annexin-A2

ANXA2

\begin{abstract}
A B S T R A C T
Current therapeutic regimes for metastatic melanoma have failed to provide robust clinical responses. Dasatinib has shown anti-proliferative and anti-invasive effects in vitro; however, not all melanoma cells tested were sensitive to dasatinib. We used 2D-DIGE analysis of phospho-enriched fractions to identify phosphoproteins involved in regulating response to dasatinib in an isogenic pair of melanoma cell lines, one sensitive to dasatinib (WM-115) and the other resistant (WM-266-4). In WM-115 cells treated with dasatinib, 18 unique protein species with altered phosphorylation levels were detected. Dasatinib treatment of WM-266-4 cells resulted in phosphoprotein alterations to four unique protein species. Four phosphorylated forms of Annexin-A2 (ANXA2) were increased in WM-115 cells treated with dasatinib, whilst dasatinib treatment did not alter ANXA2 phosphoprotein levels in WM-266-4 cells. Immunoblotting confirmed that phosphorylation of ANXA2, on tyrosine residues, was increased in WM-115 cells treated with dasatinib. Subsequent knockdown of ANXA2 by siRNA significantly inhibited proliferation of WM-115 cells but did not significantly reduce proliferation of WM-266-4 cells. Therefore, ANXA2 plays a role in regulating proliferation in dasatinib-sensitive WM-115 cells and could potentially play a role in sensitivity to dasatinib in melanoma cells.
\end{abstract}

(c) 2011 Elsevier B.V. All rights reserved.

\section{Introduction}

The prevalence of skin cancer is increasing and it is now the most frequent form of cancer in young people. Whilst melanoma skin cancer occurs worldwide at a rate of 132,000 cases each year [1], non-melanoma skin cancer makes up the majority of recorded cases with between 2 to 3 million cases diagnosed each year (www.who.int).

The increase in the number of diagnosed cases of melanoma can be explained by work and social practices; people are spending more time outside, in direct contact with sunlight. The associated exposure to powerful sunshine has been identified as a major cause of melanoma development [2].

The incidence of melanoma has increased over the last four decades, with current rates varying between 15 and 60 per 100,000 [3]. In 2006 there were 60,000 new cases of cutaneous melanoma in the European Union, and in 13,000 deaths (www.europeancancerleagues.org). Metastatic melanoma in its disseminated form is largely untreatable by

\footnotetext{
* Corresponding author. Tel.: +353 17005402; fax: +353 17005484 .

E-mail addresses: Alex.Eustace@dcu.ie (A.J. Eustace), Paul.Dowling@dcu.ie (P. Dowling), Michael.Henry@dcu.ie (M. Henry), Padraig.Doolan@dcu.ie (P. Doolan), Martin.Clynes@dcu.ie (M. Clynes), John.Crown@icorg.ie (J. Crown), Norma.ODonovan@dcu.ie (N. O'Donovan).

${ }^{1}$ Joint first authors: Alex J. Eustace and Paul Dowling.
} 
cytotoxic chemotherapy $[4,5]$. There is an urgent need for new therapeutic strategies to improve prognosis and identification of novel targets is critical for providing alternative treatment options.

Dasatinib is a potent inhibitor of BCR-Abl, SRC kinases, C-Kit, PDGFR, and ephrin-A receptor kinases[6], with an $\mathrm{IC}_{50}$ of $0.5 \mathrm{nM}$ for SRC (IC 50 $_{0}$ of $<30 \mathrm{nM}$ for the other targets) [6]. It has shown good pre-clinical activity in several cancer types including melanoma, breast, and colon cancer [7-9]. Dasatinib inhibits the growth of melanoma cell lines and reduces tumour cell migration and invasion in vitro [9-11]. SRC kinase, a target of dasatinib, is known to regulate both the growth and invasive capability of cancer cells [12]. Although inhibition of SRC kinase is implicated in response to dasatinib, specific mechanisms of response and resistance to dasatinib in melanoma cells are not yet known.

Proteomics-based screening of cell line models is an extensively used and successful approach for identifying proteins associated with drug resistance. Previously, Hong et al. and Tang et al. have employed 2D-DIGE coupled with phosphoprotein enrichment to study signal transduction pathways, in particular, identification of signal-induced changes in protein modification $[13,14]$. As dasatinib inhibits kinase-based signalling, we focussed on examining changes in phosphorylation levels in dasatinib-sensitive and resistant cells in response to treatment, in order to identify novel proteins and/or signalling pathways associated with response or resistance.

We analysed the effects of dasatinib treatment in an isogenic melanoma model. WM-115 was derived from a vertical phase primary melanoma tumour and is dasatinibsensitive, and WM-266-4 was derived from a lymph node metastatic tumour from the same patient [15] and is dasatinib-resistant. We combined phosphoprotein enrichment with 2D-DIGE technology and mass spectrometry (MS) to investigate phospho-proteome changes caused by dasatinib treatment in the two isogenic melanoma cell lines.

\section{Materials and methods}

\subsection{Cells and reagents}

WM-115 and WM-266-4 were obtained from the European Collection of Cell Cultures (ECACC). Cell lines were maintained at $37{ }^{\circ} \mathrm{C}$ with $5 \% \mathrm{CO}_{2}$ in MEM supplemented with $10 \%$ FCS, $2 \mathrm{mML}$-glutamine, $1 \mathrm{mM}$ NEAA, and $1 \mathrm{mM}$ sodium pyruvate. Stock solutions of dasatinib (10 mM) (Sequoia Research Products) were prepared in dimethyl sulfoxide (SigmaAldrich).

\subsection{Proliferation assay}

Proliferation was measured using an acid phosphatase assay. For WM-266-4 cells, $1 \times 10^{3}$ cells/well were seeded in 96-well plates, whilst WM- 115 were seeded at $2 \times 10^{3}$ cells/well. Plates were incubated overnight at $37^{\circ} \mathrm{C}$ followed by addition of drug at the appropriate concentrations and incubated for a further 5 days until control wells were $80 \%$ to $90 \%$ confluent. All media was removed and the wells were washed once with PBS. $10 \mathrm{mM}$ paranitrophenol phosphate substrate (Sigma Aldrich) in $0.1 \mathrm{M}$ sodium acetate buffer with $0.1 \%$ Triton X (Sigma Aldrich) was added to each well and incubated at $37^{\circ} \mathrm{C}$ for 2 hours. $50 \mu$ l of $1 \mathrm{M} \mathrm{NaOH}$ was added and the absorbance was read at $405 \mathrm{nM}$ (reference-620 nM), as previously described [9].

\subsection{Phospho-enrichment and preparation for 2D electrophoresis}

WM-115 and WM-266-4 cells were grown in vented $175 \mathrm{~cm}^{2}$ flasks until $90 \%$ confluent. Each cell line was then either treated for 6 hours with dasatinib at a concentration of $100 \mathrm{nM}$ or with control growth media. Triplicate samples of each treatment were prepared. Total protein was extracted and the phosphoproteins were enriched using the Pierce ${ }^{\mathrm{TM}}$ Phosphoprotein Enrichment Kit (Pierce Biotechnology). Briefly, cells were washed twice with cold HEPES buffer $(50 \mathrm{mM}, \mathrm{pH}$ 7) and lysed using the Lysis/Binding/Wash buffer provided. The lysis buffer was supplemented with CHAPS (0.25\%), sodium dodecyl sulphate, $0.1 \%$ SDS, $1 X$ Halt Protease Inhibitor EDTA-free and $1 \mathrm{X}$ Halt Phosphatase Inhibitor Cocktail (Pierce Biotechnology). After cell scraping, the lysates were placed on ice for 45 minutes, vortexing every 5 minutes and the resulting lysate was passed through an 18-gauge needle. The lysate was centrifuged at $10,000 \times \mathrm{g}$ for 20 minutes at $4{ }^{\circ} \mathrm{C}$ and the supernatant collected and stored at $-80^{\circ} \mathrm{C}$. After protein quantification by BCA assay, the concentration of each lysate was adjusted to $0.5 \mathrm{mg} / \mathrm{ml}$ and the phosphoprotein fraction of each was enriched using phosphoprotein enrichment columns supplied with the kit, according to the protocol provided. The eluted phosphoprotein fractions were concentrated using iCON concentrators (Thermo Scientific), yielding 100-150 $\mu$ l of concentrated phosphoprotein for each sample. Proteins in the phospho-enriched fraction were precipitated prior to labeling using a 2D-Cleanup Kit (Biorad). The protein pellets were resuspended in ice-cold DIGE lysis buffer $[20 \mathrm{mM}$ Tris, $7 \mathrm{M}$ Urea, $2 \mathrm{M}$ Thiourea, 4\% CHAPS pH 8.5]. Protein quantification was performed using the Quick Start Bradford Protein Assay (Biorad) and bovine serum albumin as a protein standard.

Concentrated elution fractions were resolved on 10\% SDSPAGE gels and were normalised by protein concentration (7 $\mu \mathrm{g}$ of protein per lane). To determine enrichment of both the untreated and dasatinib-treated WM-266-4 cell line, crude, void and enriched lysates were loaded onto each gel. A Phospho-specific antibody (Phospho-MAPK Tyr 204, (Cell Signalling Technology)), recognising a key regulatory protein involved in cell signalling through the ERK pathway was used to monitor binding specificity and enrichment of the Pierce Phosphoprotein Enrichment Kit. Total MAPK was also used as a control.

\subsection{Two-dimensional-differential in-gel electrophoresis (2D-DIGE)}

During this investigation, a traditional three-dye system was employed to reduce variability associated with the multiple samples being compared [16]. Phospho-enriched samples were labeled with $\mathrm{N}$-hydroxy succinimidyl ester derivatives of the cyanine dyes Cy2, Cy3, and Cy5 following a standard 
protocol [17]. Immobilised $24 \mathrm{~cm}$ linear $\mathrm{pH}$ gradient (IPG) strips, pH 3-11NL, were rehydrated in rehydration buffer (7 M Urea, 2 M Thiourea, 4\% CHAPS, 0.5\% IPG Buffer, 50 mM DTT) overnight, according to the standard guidelines. Iso-ElectricFocusing (IEF) was performed using an IPGphor apparatus (GE Healthcare) for a total of $40 \mathrm{kV} /$ hour at $20^{\circ} \mathrm{C}$. Equilibrated IPG strips were transferred onto $12.5 \%$ uniform polyacrylamide gels poured between low fluorescence glass plates. Strips were overlaid with $0.5 \% \mathrm{w} / \mathrm{v}$ low-melting-point agarose in running buffer containing bromphenol blue. Gels were run using the Ettan Dalt 12 apparatus (GE Healthcare) at $2.5 \mathrm{~W} /$ gel for 30 minutes then $100 \mathrm{~W}$ in total at $10^{\circ} \mathrm{C}$ until the dye front had run off the bottom of the gels.

\subsection{Image acquisition and analysis}

After second-dimension SDS-PAGE, gels were scanned using the Typhoon 9400 variable mode imager (GE Healthcare). Cy2 protein maps were scanned using a 488-nm laser with a 530-nm emission filter; Cy3 was scanned using a 532-nm laser with a 605-nm emission filter; Cy5 was scanned using a 635-nm laser with a 695-nm emission filter. Gels were scanned at $100 \mu \mathrm{m}$ resolution. Image analysis was performed using the DeCyderTM Software version 6.5 (GE Healthcare). Gel-to-gel matching of the standard protein maps from each gel, followed by statistical analysis of differential protein abundance between samples, was determined using the biological variation analysis module (BVA) of DeCyderTM. Analysis of variance (ANOVA) was applied to matched spots and the data were filtered to retain protein spots with $p \leq 0.05$ determined by 1-way ANOVA and a fold-change of $\geq 1$. . Using the EDA Version 1.0 (extended data analysis) module within the DeCyder software (GE Healthcare), data analysis was performed using principal components analysis (PCA) on proteins of interest [18].

\subsection{Mass spectrometry and database searching}

Preparative gels containing $400 \mu \mathrm{g}$ of protein were fixed and then post-stained with Colloidal Coomassie Blue (CCB). The CCB stained gels were scanned using the Typhoon 9400 Variable Mode Imager using the red laser without an emission filter. The subsequent gel image was cropped (ImageQuant), imported into the BVA module of DeCyder software and was matched to images generated from DIGE analysis. Spots of interest were selected and a pick list was generated and imported into the software of the Ettan Spot Picker robot (GE Healthcare).

Proteins of interest were excised from preparative gels and subjected to digestion with trypsin (Promega). The peptides resulting from tryptic digestion were subsequently desalted using ZipTipsC18 (Millipore) and eluted with a saturated solution of cyano-4-hydroxycinamic acid (CHCA; Sigma) dissolved in $50 \%$ acetonitrile and $0.1 \%$ TFA onto a 384-well MALDI plate. Samples were analysed using a 4800 Proteomics Analyzer (Applied Biosystems) and GPS Explorer software (Applied Biosystems). For MALDI-TOF/TOF-MS analysis, MS spectra were acquired in reflectron mode using 1000 shots per spectrum. Instrument calibrations were performed externally using the Pep4 calibration mixture (Laser Biolabs) and internally by the use of trypsin autolysis peaks $(842 \mathrm{~m} / \mathrm{z}, 1045 \mathrm{~m} / \mathrm{z}$, and
$2211 \mathrm{~m} / \mathrm{z}$ ). The mass range used was 800-3000 m/z. Data Explorer 4.4 (Applied Biosystems) was used for data acquisition and extraction of the monoisotopic masses. MS/MS analysis was performed by selecting 10 precursors with a minimum $\mathrm{S} / \mathrm{N}$ ratio of 40. Fragmentation of selected precursors was performed with the collision energy set at $2 \mathrm{kV}$ and atmosphere as the collision gas. A total of 1000 acquisitions were accumulated for each MS/ MS spectrum. Combined MS and MS/MS spectra were used to search for protein candidates using the UniProtKB/Swiss-Prot (Release 57.5) and NCBI-nr (April 2009 version) human protein databases with the Matrix Science offered Mascot search engine (http://www.matrixscience.com). The Mascot search parameters were (a) species, Homo sapiens; (b) allowed number of missed cleavages, 1; (c) fixed modification, carbamidomethyl cystein; (d) variable modifications, methionine oxidation, and serine/threonine/tyrosine (STY) phosphorylation; (e) peptide tolerance, \pm 50-100 ppm; (f) MS/MS tolerance, $\pm 0.3 \mathrm{Da}$; and (g) peptide charge, +1 .

Proteins not identified conclusively using MALDI-TOF/TOF MS were subjected to analysis by LC-MS. The dried peptide extracts were dissolved in $30 \mu$ of $0.1 \%$ formic acid in $2 \%$ acetonitrile and analysed by nanoLC-MS/MS using an Ultimate 3000 system (Dionex) coupled to a nanospray LTQ Orbitrap mass spectrometer (Thermo Fisher Scientific). $8 \mu$ l of each sample was concentrated and desalted on RPC trap columns (Zorbax 300SB C18, $0.3 \mathrm{~mm} \times 5 \mathrm{~mm}$, Agilent Technologies, and the peptides were separated on a nano-RPC column (Zorbax 300SB C18, $0.075 \mathrm{~mm} \times 100 \mathrm{~mm}$, Agilent Technologies) using a linear acetonitrile gradient from $0 \%$ to $65 \%$ ACN (Sigma) over 60 minutes. All buffers used for nano LC separation contained $0.1 \%$ formic acid (Fluka) as the ion pairing reagent. The flow rate was set at $300 \mathrm{nl} /$ minute. The LTQ Orbitrap was operated in data-dependent acquisition mode with Xcalibur software. Survey scan MS data were acquired in the Orbitrap on the 300$2000 \mathrm{~m} / \mathrm{z}$ mass range with the resolution set to a value of 60,000 at $m / z 400$. The five most intense ions per survey scan were selected for MS/MS fragmentation and the resulting fragments were analysed in the linear trap. Collision energy was set to $35 \%$. Dynamic exclusion was employed within 60 seconds to prevent repetitive selection of the same peptide. Full scan mass spectra were recorded in profile mode and tandem mass spectra in centroid mode. The peptides were identified using the information in the tandem mass spectra by searching against the UniProtKB/Swiss-Prot (Release 57.5) and NCBI-nr (April 2009 version) human protein databases using SEQUEST. For protein identification, artificial modifications of peptides (carbamidomethylation of cysteines, partial oxidation of methionines, and serine/threonine/tyrosine (STY) phosphorylation) were considered. Searches were also carried out allowing for one missed cleavage and mass tolerances in MS and MS/MS were set to $10 \mathrm{ppm}$ and $0.5 \mathrm{Da}$, respectively. Criteria for positive identification of proteins included at least two identified peptides and a peptide XCorr of $>2$ for doubly charged ions, $>2.2$ for triply charged ions, and $>3$ for quadruply charged ions.

\subsection{Protein extraction}

$500 \mu \mathrm{L}$ RIPA buffer (Sigma-Aldrich) with 1× protease inhibitors, $2 \mathrm{mM}$ phenylmethanesulphonylfluoride (PMSF), and $1 \mathrm{mM}$ 
sodium orthovanadate (all Sigma-Aldrich) was added to cells and incubated on ice for 20 minutes. Following centrifugation at $16,000 \times \mathrm{g}$ for 5 minutes at $4{ }^{\circ} \mathrm{C}$ the resulting lysate was stored at $-80^{\circ} \mathrm{C}$. Protein quantification was performed using the Quick Start Bradford Protein Assay (Biorad) using bovine serum albumin as a protein standard.

\subsection{Coomassie staining}

$10 \mu \mathrm{g}$ protein in sample buffer (3.12 m M Tris-HCl; 5\% Sodium dodecyl sulphate (SDS); $2.5 \mathrm{ml}$ beta-mercaptoethanol; 29\% glycerol; $0.1 \%$ bromophenol blue made up to $20 \mathrm{ml}$ with $\mathrm{dH}_{2} \mathrm{O}$ ) was heated to $95{ }^{\circ} \mathrm{C}$ for 5 minutes and loaded onto $12 \%$ NuPAGE Bis-Tris gels (Invitrogen) and electrophoretically separated using a MOS/SDS buffer. The samples were run according to the manufacturer's instructions and were stained using CCB (Sigma). The gel was scanned on an Image Scanner (GE Healthcare) using LabScan v5.0 (GE Healthcare).

\subsection{Western blotting}

$40 \mu \mathrm{g}$ of protein in sample buffer (3.12 m M Tris- $\mathrm{HCl}$; $5 \%$ sodium dodecyl sulphate (SDS); $2.5 \mathrm{ml}$ beta-mercaptoethanol; $29 \%$ glycerol; $0.1 \%$ bromophenol blue made up to $20 \mathrm{ml}$ with $\mathrm{dH}_{2} \mathrm{O}$ ) was heated to $95^{\circ} \mathrm{C}$ for 5 minutes and proteins were separated on $10 \%$ polyacrylamide gels (Lonza). The protein was transferred to Hybond-ECL nitrocellulose membrane (Amersham Biosciences). The membrane was blocked with $5 \%$ milk powder (Biorad) in 0.1\% PBS-Tween at room temperature for 1 hour, then incubated overnight at $4{ }^{\circ} \mathrm{C}$ in $1 \mu \mathrm{g} / \mathrm{ml}$ primary antibody for ANXA2 (BD Biosciences); phosphotyrosine, phosphoserine, SRC kinase, p-SRC (Y418) (Millipore), p-MAPK (Tyr 204), MAPK (Cell signalling) and $\alpha$-tubulin (Sigma Aldrich) with $0.1 \%$ PBS-Tween in $5 \%$ milk powder. The membrane was washed three times with $0.5 \%$ PBS-Tween and then incubated at room temperature with $1 \mu \mathrm{g} / \mathrm{ml}$ anti-mouse secondary antibody (Sigma Aldrich) for ANXA2, phosphotyrosine, phosphoserine, SRC and $\alpha$-tubulin and $0.3 \mu \mathrm{g} / \mathrm{ml}$ anti-rabbit secondary antibody (Sigma Aldrich) for p-SRC (Y418), p-MAPK (Tyr 204), and MAPK in $5 \%$ milk powder with $0.5 \%$ PBS-Tween for 1 hour. The membrane was washed three times with $0.5 \%$ PBS-Tween followed by one wash with PBS alone. Detection was performed using Luminol (Santa Cruz Biotechnology) or ECL Advance (GE Healthcare).

\subsection{Immunoprecipitation}

Immunoprecipitation was performed using the Catch and Release $₫$ reversible immunoprecipitation system (Millipore). Briefly, spin columns were washed 3 times with $400 \mu \mathrm{l}$ of $1 \mathrm{X}$ Catch and Release wash buffer. $500 \mu \mathrm{g}$ of cell lysate was added to the column together with 2-3 $\mu$ g of antibody per sample, $10 \mu \mathrm{l}$ of Catch and Release antibody ligand and the final volume was made up to $500 \mu \mathrm{l}$ with $1 \mathrm{X}$ wash buffer. Capped sample columns were then incubated overnight on a shaker at $4{ }^{\circ} \mathrm{C}$. Columns were centrifuged at $2000 \times \mathrm{g}$ for 30 seconds, washed with $400 \mu \mathrm{l} 1 \mathrm{X}$ wash buffer, centrifuged again at $2000 \times g$ for 30 seconds and the supernatant removed. This process was repeated twice. $70 \mu$ l of denaturing elution buffer with $5 \%$ beta-mercaptoethanol was added and incubated for 5 minutes. The column was centrifuged for 1 minute at $2000 \times \mathrm{g}$. This procedure was repeated three times and each eluent collected into a separate tube. Samples were heated to $95^{\circ} \mathrm{C}$ for 5 minutes and stored at $-20^{\circ} \mathrm{C}$.

\subsection{Small interfering RNA (siRNA) transfection}

A siRNA molecule targeting kinesin and a scrambled sequence siRNA molecule (Ambion) were used as positive and negative transfection controls. Each siRNA molecule was transfected at a final concentration of $30 \mathrm{nM} .5 \times 10^{4}$ and $1.5 \times 10^{5}$ cells were resuspended in MEM media for 24-well and 6-well plates respectively and incubated overnight at $37^{\circ} \mathrm{C}$. Each siRNA (ANXA2 siRNA-ON-TARGETplus SMART pool (Thermo); kinesin and scrambled (Applied Biosystems)) and Lipofectamine 2000 transfection agent ( $3 \mu \mathrm{l}$ for 6 -well plates; $0.75 \mu$ l for 24well plates) were diluted in Gibco ${ }^{\mathrm{TM}}$ Opti-MEM reduced serum medium (Invitrogen), and incubated at room temperature (RT) for 5 minutes. Diluted Lipofectamine 2000 was added to each diluted siRNA and incubated for a further 20 minutes at RT and the transfection mix was then added. After 24 hours, the transfection media was replaced with MEM media supplemented with $10 \%$ FCS. Six-well plates were used to prepare lysates after 72 hours. Cells in 24-well plates were harvested after 72 hours and counted using Guava Viacount (Millipore) on the Guava EasyCyte.

\section{Results}

\subsection{Sensitivity to dasatinib in WM-115 and WM-266-4 melanoma cell lines}

In proliferation assays, the primary melanoma cell line WM115 displayed greater sensitivity to dasatinib than the metastatic cell line WM-266-4, which is derived from the same patient [15]. The concentration of dasatinib required to inhibit $50 \%$ of the proliferation $\left(\mathrm{IC}_{50}\right)$ of $\mathrm{WM}-115$ was of $79.3 \mathrm{nM}$ $( \pm 11.7 \mathrm{nM})$. In WM-266-4 cells, dasatinib did not achieve $50 \%$ inhibition of growth. The maximum growth inhibition achieved was $13 \%$ at $100 \mathrm{nM}$ dasatinib (Fig. 1A). SRC is expressed and phosphorylated on tyrosine 418 (Y418) in both WM-115 and WM-266-4 cells (Fig. 1B). Treatment with $100 \mathrm{nM}$ dasatinib for 6 hours resulted in the inhibition of activation of p-SRC Y418 levels in both cells lines. The reduction in p-SRC activation occurred regardless of the effect that dasatinib had on proliferation levels.

\subsection{Phosphoproteomic profiling of dasatinib-treated cells}

To demonstrate phosphoprotein enrichment using the Pierce ${ }^{\mathrm{TM}}$ Phosphoprotein Enrichment Kit, a 1D gel was run using crude, void, and phosphoprotein-enriched samples. The void samples were the flow-through from the phosphoprotein enrichment column and therefore should contain little phosphorylated protein. The Coomassie -stained gel demonstrated that all 3 proteome fractions are different indicating that fractionation of the crude sample using the enrichment kit was successful (Fig. 1C). Further Western blot analysis of the equally loaded 

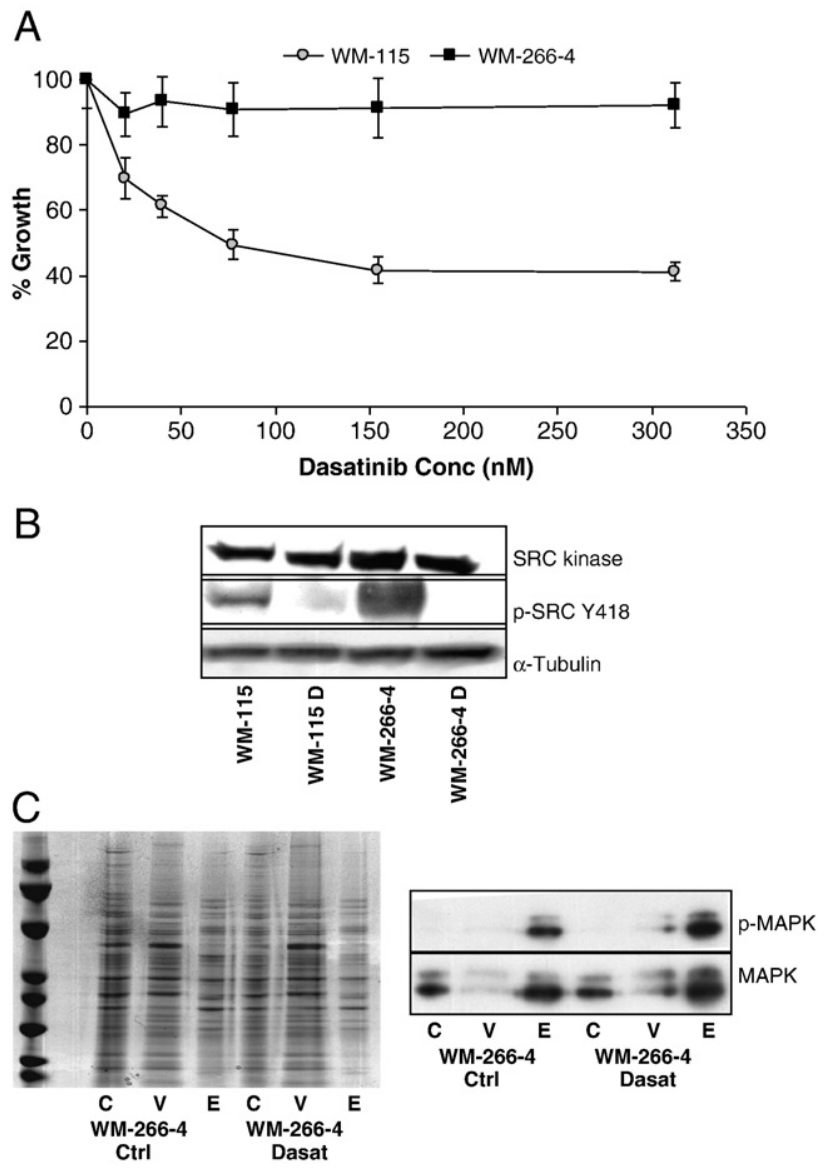

Fig. 1 - A. \%Growth inhibition of WM-115 and WM-266-4 cells when treated with $100 \mathrm{nM}$ dasatinib in a 5-day growth assay as determined by acid phosphatase. B. Western blotting analysis of SRC kinase and $\alpha$-tubulin expression and levels of p-SRC Y418 in WM-115 and WM-266-4 cells with and without $100 \mathrm{nM}$ dasatinib for 6 hours. C. A Coomassie stained gel displaying the crude (C), void (V), and phospho-enriched (E) fractions of WM-266-4 cells with and without dasatinib treatment separated by 1D gel fractionation. Western blotting analysis of p-MAPK (Y204) and MAPK in crude (C), void (V), and phospho-enriched (E) fractions of WM-266-4 cells with and without dasatinib treatment.

crude, void, and phosphoprotein-enriched samples from WM266-4 cells, with and without dasatinib treatment, were analysed using a phospho-specific antibody recognising mitogen-activated protein kinase (p-MAPK). Western blotting demonstrated an increased level of phosphorylated MAPK protein in samples of both phospho-enriched WM-266-4 parental and drug-treated cells, compared to the crude and void fractions (Fig. 1C). Incubation of the blots with an antibody to total MAPK demonstrated the presence of this protein in all samples.

Using MASCOT and SEQUEST web-based protein prediction tools, we examined peptide modifications including phosphorylation. We detected potential phosphorylation sites in 16 of the 34 proteins analysed (47\%) (Tables 1 and 2). This suggests that the phosphoprotein enrichment procedure selectively increased phosphoproteins in the protein samples analysed. Furthermore, the number of potential phosphorylation sites identified may have been limited by the sequence coverage obtained for some of the proteins. For the 34 proteins identified, the sequence coverage ranged from $7 \%$ to $69 \%$ with an average coverage of $38 \%$. Phosphorylation sites were only identified on proteins which attained greater than 33\% sequence coverage $(n=25)$. Of proteins with greater than $33 \%$ sequence coverage, potential phosphorylation events were detected in $64 \%(16 / 25)$ of cases.

Following 2D-DIGE analysis of phosphoprotein-enriched lysates from WM-115, dasatinib-treated WM-115, WM-266-4 and dasatinib-treated WM-266-4 cells, approximately 1200 protein spots were detected on each gel (Fig. 2). Twenty-one proteins, which were altered in WM-115 compared to dasatinib-treated WM-115 cells and WM-266-4 compared to dasatinib-treated WM-266-4 cells ( $\geq 1.2$-fold, $p \leq 0.05$ determined by 1-way ANOVA), were excised from 2D gels, subjected to tryptic digestion, and the resulting peptides were analysed by mass spectrometry (MALDI-TOF/TOF or LC-MS). Of these 21 unique protein species identified, 18 were found to be uniquely associated with dasatinib treatment in the WM-115 cells and demonstrated fold changes ranging from -2.98 to +7.03 $(\mathrm{p} \leq 0.05$ determined by 1 -way ANOVA) (Table 1). Four unique phosphoproteins were found to be uniquely associated with dasatinib treatment in the WM-266-4 cells, with fold changes ranging from -1.64 to $-1.22(\mathrm{p} \leq 0.05)$ (Table 2$)$. Three phosphoproteins were altered in both cell lines in response to dasatinib treatment, namely PRDX2, RDX, and GRP78.

The proteins that showed the greatest fold change in response to dasatinib treatment in WM-115 cells included 2 spots identified as protein disulfide isomerase-related protein 5 (PDIA5), two moesin (MSN) and two radixin (RDX) isoforms, which were all reduced in dasatinib-treated WM-115 cells (Table 1). Dasatinib treatment of WM-115 cells also resulted in increased abundance of 14 phosphoproteins, which were not altered in dasatinib-treated WM-266-4 cells.

In WM-115 cells, treatment with dasatinib resulted in increased abundance of 4 phospho-enriched isoforms of Annexin-A2 (ANXA2) (3.06-fold, 3.02-fold, 2.17-fold, and 1.97fold) (Fig. 3A-D, spot numbers 26-29 from Table 1). None of these ANXA2 isoforms were significantly altered in dasatinibtreated WM-266-4 cells. Another isoform of ANXA2 was also identified in our analysis (Fig. 3e). Dasatinib treatment of WM115 cells did not alter levels of this isoform (fold change, 1.10), whilst dasatinib treatment of WM-266-4 cells resulted in a slight decrease (fold change, -1.24) but this did not achieve statistical significance.

The four phosphoprotein species uniquely altered in WM266-4 cells were decreased in response to dasatinib treatment. The two proteins that showed the greatest fold changes were annexin-A3 (ANXA3), which was decreased by 1.64-fold, and high mobility group protein B1 (HMGB1), which was decreased by 1.57 -fold (Table 2 ).

\subsection{Multivariate analysis}

Multivariate analysis was performed, using the DeCyder-EDA module. The analysis was performed on differentially regulated proteins in untreated versus dasatinib-treated WM-115 
Table 1 - Identified phosphoproteins uniquely altered in dasatinib-treated WM-115 cells. Phosphoproteins, which demonstrated a fold-change of $\geq 1.2$ and a significant $p$ value $(\leq 0.05)$, were included for analysis.

\begin{tabular}{|c|c|c|c|c|c|c|c|c|c|c|c|}
\hline Master no. & Protein ID & Gene Symbol & $\begin{array}{l}\text { Accession } \\
\text { number }\end{array}$ & $\begin{array}{c}\text { Fold } \\
\text { change }\end{array}$ & $p$ value & XC-score ${ }^{a}$ & $\begin{array}{l}\text { Mascot } \\
\text { score }^{b}\end{array}$ & $\begin{array}{l}\text { \%Sequence } \\
\text { coverage }\end{array}$ & $\begin{array}{l}\text { Peptides } \\
\text { matched }\end{array}$ & $\begin{array}{l}\text { LC/MS or } \\
\text { MALDI } \\
\text { TOF/TOF }\end{array}$ & $\begin{array}{c}\text { STY } \\
\text { residue } \\
\text { modified }\end{array}$ \\
\hline 1 & Moesin & MSN & 127234 & -2.98 & $1.00 \mathrm{e}-30$ & 90 & - & 33 & 9 & LC/MS & $\mathrm{N}$ \\
\hline 2 & Peroxiredoxin 2 isoform $b$ & PRDX2 & 2507169 & -2.69 & $2.07 \mathrm{e}-12$ & 50 & - & 37 & 5 & LC/MS & $\mathrm{Y}$ \\
\hline 3 & Radixin & $\mathrm{RDX}$ & 464541 & -2.46 & $7.03 e-12$ & 120 & - & 33 & 12 & LC/MS & Y \\
\hline 4 & Transketolase & TKT & 1729976 & -2.38 & $1.00 \mathrm{e}-30$ & 120 & - & 36 & 12 & LC/MS & $\mathrm{Y}$ \\
\hline 5 & Moesin & MSN & 127234 & -2.3 & $7 e-005$ & - & 93 & 33 & 9 & MALDI & $\mathrm{Y}$ \\
\hline 6 & Radixin & RDX & 464541 & -1.91 & $9.85 e-10$ & 100 & - & 26 & 10 & LC/MS & $\mathrm{N}$ \\
\hline 7 & Serum Albumin & ALB & 113576 & -1.9 & $6.7 e-005$ & - & 47 & 7 & 5 & MALDI & $\mathrm{N}$ \\
\hline 8 & Protein disulfide isomerise-related protein 3 & PDIA3 & 2507461 & -1.9 & $2.6 \mathrm{e}-055$ & - & 597 & 49 & 36 & MALDI & $\mathrm{Y}$ \\
\hline 9 & Radixin & RDX & 464541 & -1.84 & $2.82 \mathrm{e}-09$ & 50 & - & 22 & 5 & LC/MS & $\mathrm{N}$ \\
\hline 10 & Protein disulfide isomerise-related protein 5 & PDIA5 & 1710248 & -1.73 & $1.3 e-006$ & - & 110 & 31 & 15 & MALDI & $\mathrm{N}$ \\
\hline 11 & Protein disulfide isomerise-related protein 5 & PDIA5 & 1710248 & -1.66 & $3.3 e-006$ & - & 106 & 31 & 14 & MALDI & $\mathrm{N}$ \\
\hline 12 & Glyceraldehyde-3-phosphate dehydrogenase & GAPDH & 120649 & -1.44 & $1.82 \mathrm{e}-10$ & 40 & - & 18 & 4 & LC/MS & $\mathrm{N}$ \\
\hline 13 & Moesin & MSN & 127234 & -1.41 & $1 e-008$ & - & 131 & 39 & 13 & MALDI & $\mathrm{Y}$ \\
\hline 14 & Annexin A1 & ANXA1 & 113944 & -1.37 & $3.44 \mathrm{e}-14$ & 140 & - & 55 & 14 & LC/MS & $\mathrm{N}$ \\
\hline 15 & Pyruvate kinase M2 & PKM2 & 5702302 & -1.34 & $2.6 \mathrm{e}-012$ & - & 167 & 69 & 4 & MALDI & $\mathrm{Y}$ \\
\hline 16 & Glucose-6-phosphate 1-dehydrogenase & G6PD & 116242483 & -1.34 & $2.03 \mathrm{e}-12$ & 180 & - & 62 & 18 & LC/MS & $\mathrm{N}$ \\
\hline 17 & Alpha-enolase & ENO1 & 119339 & -1.31 & $1.59 \mathrm{e}-08$ & 40 & - & 29 & 4 & LC/MS & $\mathrm{N}$ \\
\hline 18 & Protein disulfide isomerise-related protein 5 & PDIA5 & 1710248 & 1.34 & 0.036 & - & 66 & 30 & 13 & MALDI & $\mathrm{N}$ \\
\hline 19 & Peroxiredoxin-4 & PRDX4 & 3024727 & 1.36 & $2.22 \mathrm{e}-14$ & 80 & - & 38 & 8 & LC/MS & $\mathrm{Y}$ \\
\hline 20 & Alpha-actinin-4 & ACTN4 & 13123943 & 1.38 & $2.57 \mathrm{e}-07$ & 40 & - & 7 & 4 & LC/MS & $\mathrm{N}$ \\
\hline 21 & Annexin-A1 & ANXA1 & 113944 & 1.4 & $2.6 \mathrm{e}-011$ & - & 157 & 39 & 17 & MALDI & $\mathrm{N}$ \\
\hline 22 & Glyceraldehyde-3-phosphate dehydrogenase & GAPDH & 120649 & 1.43 & $3.33 e-09$ & 40 & - & 25 & 4 & LC/MS & $\mathrm{N}$ \\
\hline 23 & Glyceraldehyde-3-phosphate dehydrogenase & GAPDH & 120649 & 1.43 & $1.1 \mathrm{e}-15$ & 232 & - & 68 & 16 & LC/MS & $\mathrm{N}$ \\
\hline 24 & Actin B & АСТВ & 15277503 & 1.51 & $1.3 e-007$ & - & 120 & 27 & 15 & MALDI & $\mathrm{N}$ \\
\hline 25 & Stress-70 protein & GRP75 & 21264428 & 1.79 & $5.55 e-14$ & 240 & - & 48 & 24 & LC/MS & $\mathrm{Y}$ \\
\hline 26 & Annexin A2 & ANXA2 & 113950 & 1.97 & $2.6 \mathrm{e}-013$ & - & 177 & 35 & 18 & MALDI & $\mathrm{N}$ \\
\hline 27 & Annexin-A2 & ANXA2 & 113950 & 2.17 & $3.33 e-16$ & - & 251 & 50 & 23 & MALDI & $\mathrm{Y}$ \\
\hline 28 & Annexin-A2 & ANXA2 & 113950 & 3.02 & $8.2 \mathrm{e}-023$ & - & 272 & 46 & 24 & MALDI & $\mathrm{Y}$ \\
\hline 29 & Annexin-A2 & ANXA2 & 113950 & 3.06 & $6.5 \mathrm{e}-038$ & - & 613 & 63 & 32 & MALDI & $\mathrm{Y}$ \\
\hline 30 & S100A10 & S100A10 & 4388970 & 7.03 & $4.1 \mathrm{e}-009$ & - & 135 & 41 & 8 & MALDI & $\mathrm{Y}$ \\
\hline
\end{tabular}


Table 2 -Identified phosphoproteins uniquely altered in dasatinib-treated WM-266-4 cells. Phosphoproteins, which demonstrated a fold-change of $\geq 1.2$ and a significant $p$ value $(\leq 0.05)$, were included for analysis.

\begin{tabular}{|c|c|c|c|c|c|c|c|c|c|c|c|}
\hline $\begin{array}{c}\text { Master } \\
\text { no. }\end{array}$ & Protein ID & $\begin{array}{l}\text { Fold } \\
\text { change }\end{array}$ & $\begin{array}{l}\text { Gene } \\
\text { Symbol }\end{array}$ & $\begin{array}{c}\text { XC- } \\
\text { score }^{a}\end{array}$ & $\begin{array}{l}\text { Mascot } \\
\text { score }^{b}\end{array}$ & $\begin{array}{l}\text { \%Sequence } \\
\text { coverage }\end{array}$ & $p$ value & $\begin{array}{l}\text { Accession } \\
\text { number }\end{array}$ & $\begin{array}{l}\text { Peptides } \\
\text { matched }\end{array}$ & $\begin{array}{c}\text { LC/MS or } \\
\text { MALDI } \\
\text { TOF/TOF }\end{array}$ & $\begin{array}{l}\text { STY } \\
\text { residue } \\
\text { modified }\end{array}$ \\
\hline 31 & Annexin-A3 & -1.64 & ANXA3 & 110 & - & 38 & $2.03 e-11$ & 113954 & 11 & LC/MS & $\mathrm{Y}$ \\
\hline 32 & $\begin{array}{l}\text { High mobility group } \\
\text { protein B1 }\end{array}$ & -1.57 & HMGB1 & 40 & - & 54 & $1.84 \mathrm{e}-07$ & 123369 & 4 & LC/MS & $\mathrm{N}$ \\
\hline 33 & $\begin{array}{l}\text { Heat shock cognate } \\
71 \mathrm{kDa} \text { protein }\end{array}$ & -1.33 & HSC71 & 140 & - & 34 & $1.67 e-14$ & 123648 & 14 & LC/MS & $\mathrm{Y}$ \\
\hline 34 & $\begin{array}{l}\text { Glucose-6-phosphate } \\
\text { 1-dehydrogenase }\end{array}$ & -1.22 & G6PD & 116 & - & 55 & $2.86 \mathrm{e}-12$ & 116242483 & 16 & LC/MS & Y \\
\hline
\end{tabular}

cells and in untreated versus dasatinib-treated WM-266-4 cells. Principal component analysis presents the greatest variance of the data set on the abscissa (principal component $1, \mathrm{PC} 1,69.9 \%$ of the variance) and the second greatest variance of the data on the ordinate (principal component 2, PC2, 23.4\% of the variance). Together, both PC1 and PC2 accounted for $93.3 \%$ of the variance. Samples from each cell line clustered together indicating limited variance within each group and distinct differences between cell lines. The spot maps (score plot) from untreated WM-266-4 cells and dasatinib-treated WM-266-4 cells clustered together, indicating limited variance between these two phenotypes. However, untreated WM-115 and dasatinib-treated WM-115 cells cluster at different locations from each other and from both untreated and treated WM-266-4 cells. This indicates that both untreated and treated WM-115 cells are distinct from WM-266-4 and dasatinibtreated WM-266-4 cells as well as from each other in terms of consistent differences in phosphoprotein levels (Fig. 4).

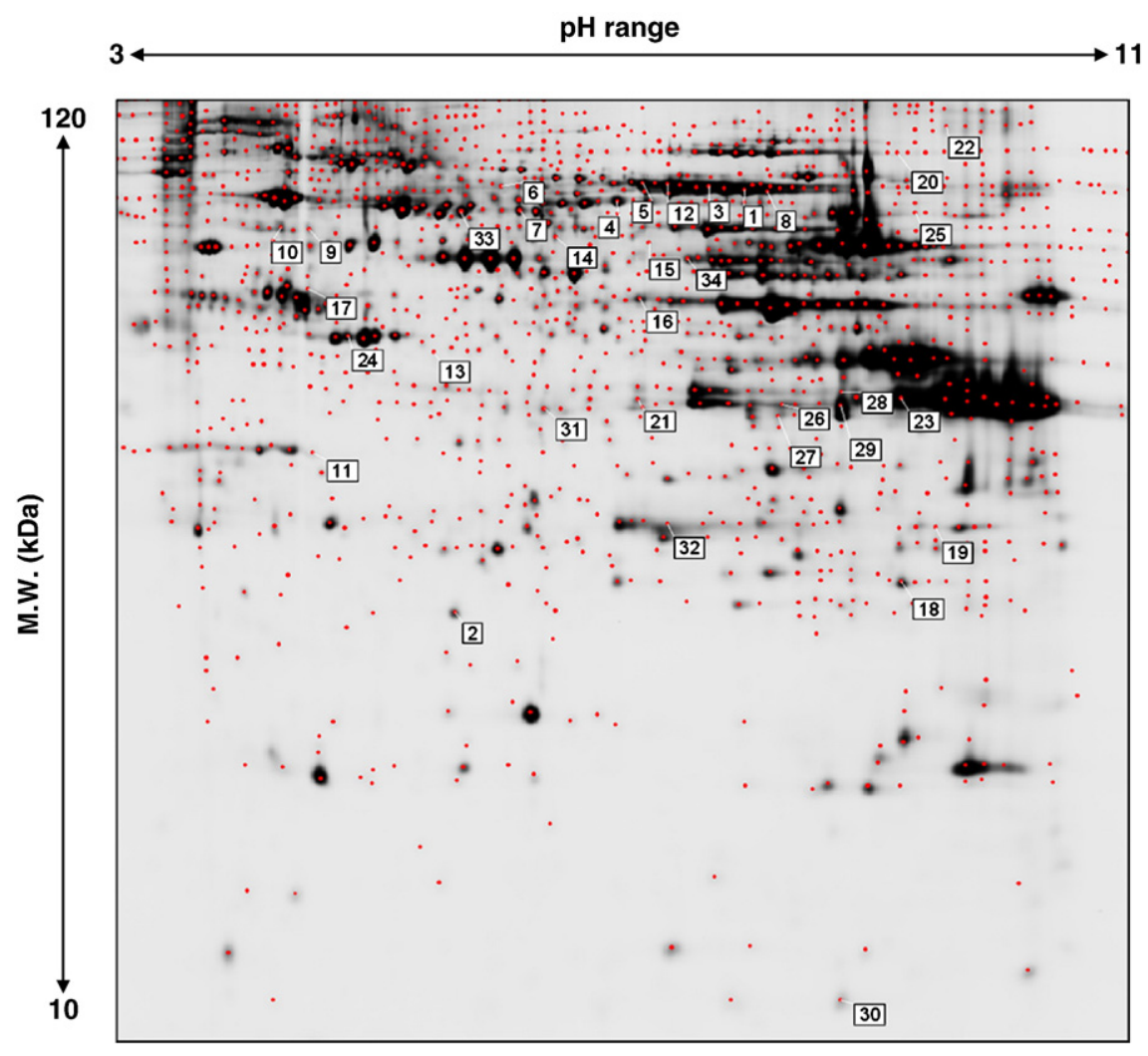

Fig. 2 - Differentially regulated phosphoproteins associated with sensitivity or resistance to dasatinib. Preparative gel showing the exact locations for the 34 differentially expressed phosphoproteins. These 34 phosphoproteins (30 uniquely associated with the WM-115/WM-115 dasatinib comparison and 4 uniquely associated with the WM-266-4/WM-266-4 dasatinib comparison) were subsequently identified by MALDI-TOF/TOF MS or LC-MS ( $p<0.05$ determined by 1 -way ANOVA) in the pH range 3-11 NL (left to right) and molecular weight range of approximately 10-120 kDa. Proteins were labelled numerically for visual clarity and are outlined in Table 1 and Table 2. 

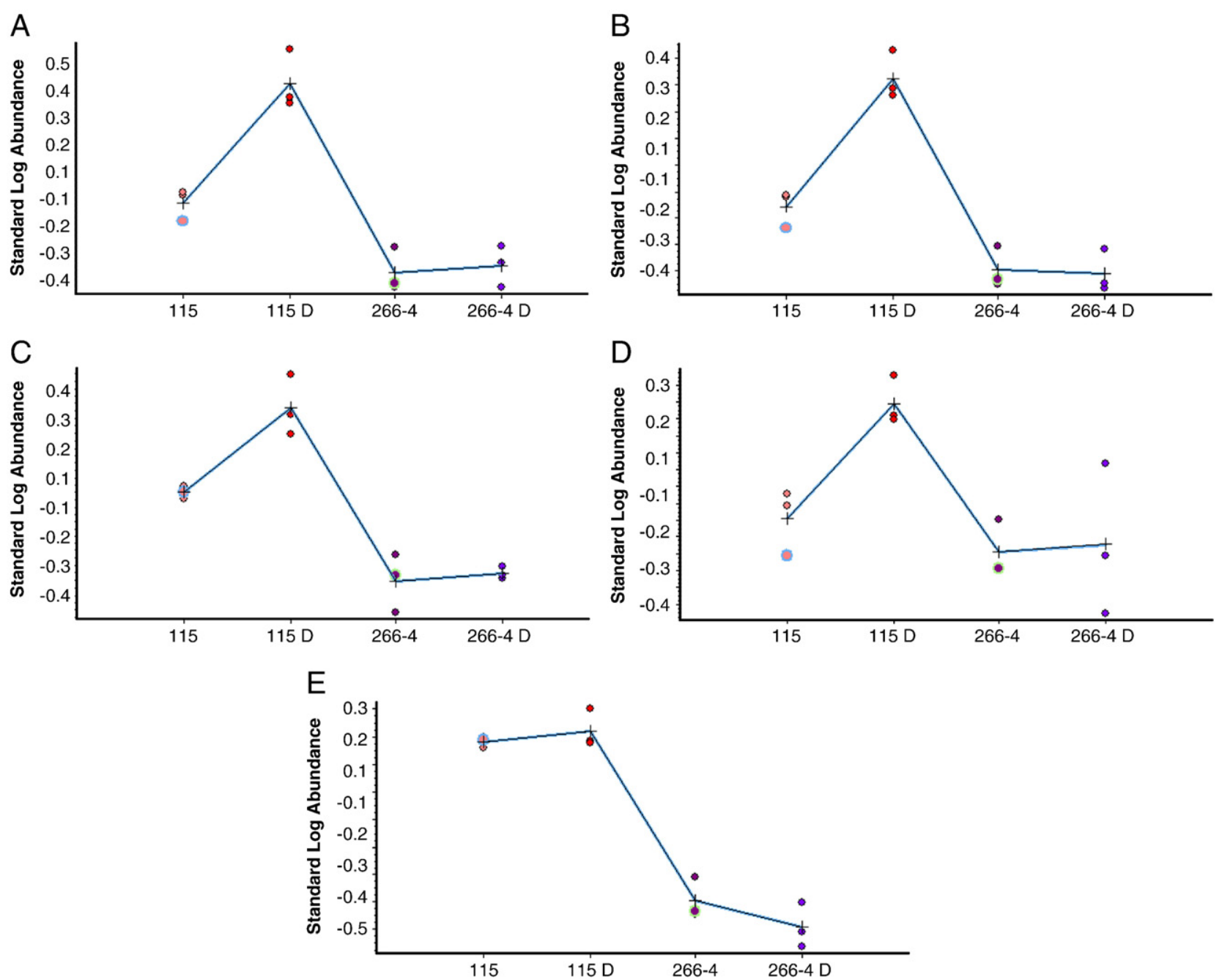

Fig. 3 - Phospho-enriched Annexin-A2 isoforms in WM-115, WM-115 dasatinib-treated (WM-115 D), WM-266-4, and WM-266-4 dasatinib-treated (WM-266-4 D) cells. The $y$-axis represents the standardised log abundance of protein abundance.

\subsection{ANXA2 in melanoma cells}

As several isoforms of ANXA2 were altered in response to dasatinib treatment, ANXA2 was selected for further analysis in the melanoma cell lines. ANXA2 protein was detected in both WM-115 and WM-266-4 cell lines by Western blotting, with slightly higher levels in WM-115 cells compared to WM266-4 cells (Fig. 5A). Based on previously published phosphoproteomic analyses, ANXA2 has 5 potential serine phosphorylation sites and 14 potential tyrosine phosphorylation sites (www.phosphosite.org) [19]. Our 2D-DIGE phospho-proteomic analysis indicated that the levels of ANXA2 phosphoproteins are higher in WM-115 cells compared to WM-266-4 cells. Furthermore, four of the identified phospho-ANXA2 spots were significantly increased in WM-115 cells in response to dasatinib treatment.

For identification of peptide modifications of the 4 isoforms of ANXA2, the search included phosphorylation (STY) modification analysis. We detected a number of potential phosphorylation sites in the 4 ANXA2 isoforms (Table 3). Two potential phosphorylation sites, within residues $28-38$, were detected on spot 27, whilst one potential phosphorylation site was detected on spot 29 in the same peptide (KAYTNFDAERD). Three potential phosphorylation sites were detected on spot 28; one on peptide 232-245 (R.YKSYSPYDMLESIR.K) and two on peptide 274-281 (R.LYDSMKGK.G). No potential phosphorylation sites were detected on spot 26.

Tyrosine phosphorylation of ANXA2 was assessed by ANXA2 immunoprecipitation followed by immunoblotting with an anti-phosphotyrosine antibody. Dasatinib treatment resulted in a slight increase in ANXA2 phosphotyrosine levels in WM-115 (Fig. 5B), whereas a slight decrease was observed in dasatinib-treated WM-266-4 cells. Very low levels of serine phosphorylation were detected on ANXA2 in both WM-115 and WM-266-4 cells.

We also assessed the effects of ANXA2 siRNA on proliferation in WM-115 and WM-266-4 cells. ANXA2 siRNA significantly reduced ANXA2 expression ( $p=0.04)$ in WM-115 cells and caused significant inhibition of proliferation in WM-115 cells $(42.3 \pm$ $12.3 \%, p=0.04$ ) compared to the scrambled siRNA (Fig. 6).

ANXA2 siRNA also significantly reduced ANXA2 expression compared to scrambled siRNA $(p=0.01)$ in WM-266-4 cells 


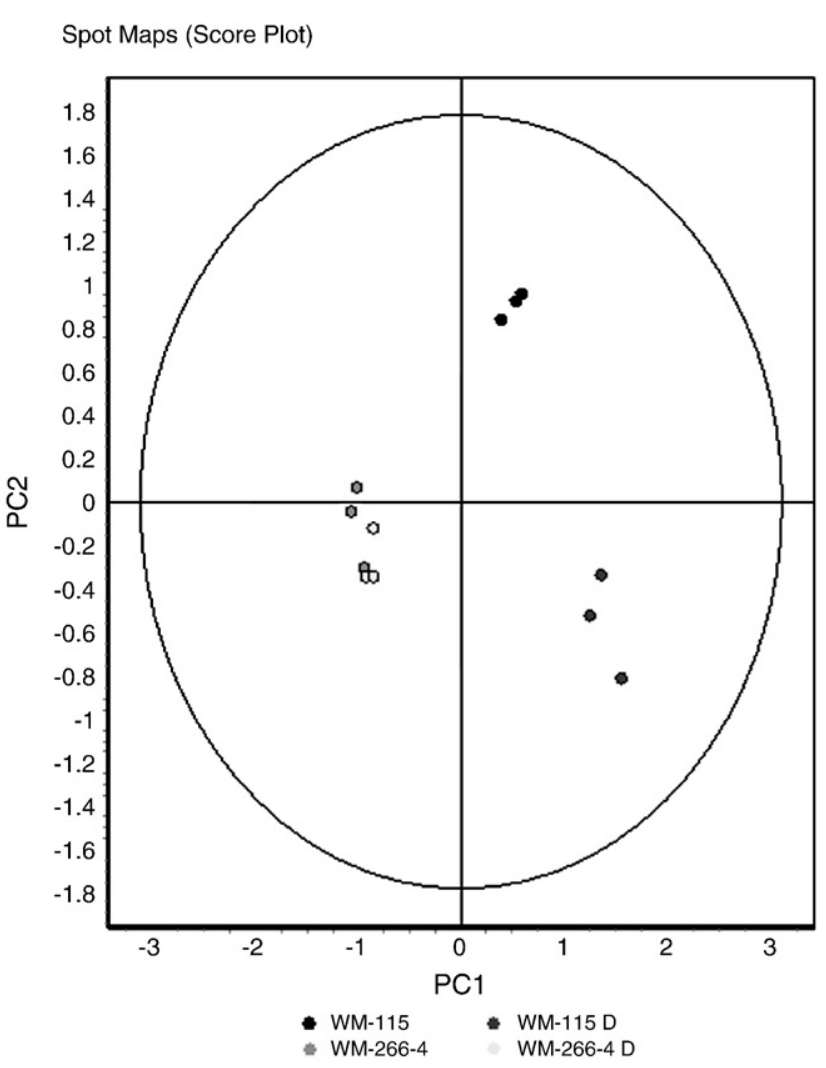

Fig. 4 - Principal component analysis (PCA) showing the position of the four cell line samples, WM-115,

WM-115 D, WM-266-4, and WM-266-4 D based on the first two ordination axes, PC1 (abscissa) and PC2 (ordinate). PC1 accounted for $69.9 \%$ of the variance and PC2 accounted for 23.4\% of the variance. Together, both PC1 and PC2 accounted for $93.3 \%$ of the variance.

(Fig. 7). ANXA2 siRNA did not significantly reduce proliferation $(13.8 \pm 8.5 \%, p=0.36)$ in WM-266-4 cells, compared to the scrambled siRNA.

A
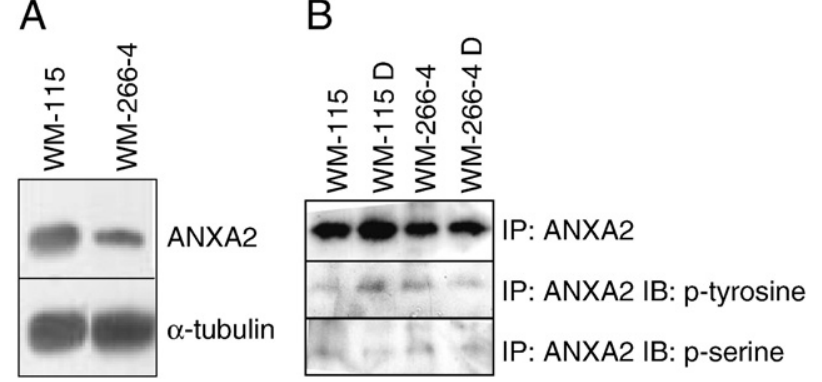

Fig. 5 - Western blot analysis of (A) ANXA2 and $\alpha$-tubulin in WM-115 and WM-266-4 melanoma cell lines. (B) ANXA2 immunoprecipitation (IP) and detection of the ANXA2 tyrosine and serine residues by immunoblotting using phosphotyrosine or phosphoserine antibodies in WM-115 and WM-266-4 cells with and without $100 \mathrm{nM}$ dasatinib for 6 hours.
Table 3-Matched peptide information for identified

isoforms of ANXA2 proteins, showing fold change in

ANXA2 abundance between untreated and dasatinib-

treated WM-115 cells, MASCOT scores and \%coverage

obtained for the matched peptides. Peptide sequences

with potential phosphorylation sites and the number of

potential phosphorylation sites detected are listed.

Residues marked as bold and underlined indicate

potential serine $(\mathrm{S})$, threonine $(\mathrm{T})$, or tyrosine $(\mathrm{Y})$

phosphorylation sites.

\begin{tabular}{|c|c|c|c|c|c|}
\hline & 26 & 27 & 28 & 29 \\
\hline \multicolumn{2}{|c|}{ Fold change } & 3.02 & 1.97 & 3.06 & 2.17 \\
\hline \multicolumn{2}{|c|}{ MASCOT score } & 266 & 188 & 605 & 160 \\
\hline \multicolumn{2}{|c|}{ \%Coverage } & $48 \%$ & $51 \%$ & $59 \%$ & $45 \%$ \\
\hline \multicolumn{2}{|c|}{$\begin{array}{l}\text { Total no. of potential phosphate } \\
\text { groups }\end{array}$} & 0 & 2 & 3 & 1 \\
\hline \multicolumn{6}{|c|}{ Peptide sequences and no. of phosphate groups identified } \\
\hline $11-28$ & $\begin{array}{l}\text { K.LSLEGDHSTPPSAYGS } \\
\text { VK.A }\end{array}$ & 0 & 0 & 0 & 0 \\
\hline $28-38$ & KAYTNFDAERD & 0 & 2 & 0 & 1 \\
\hline $50-63$ & K.GVDEVTIVNILTNR.S & 0 & 0 & 0 & 0 \\
\hline 69-77 & R.QDIAFAYQR.R & 0 & 0 & 0 & \\
\hline 89-104 & K.SALSGHLETVILGLLK.T & & & 0 & \\
\hline 105-115 & K.TPAQYDASELK.A & 0 & 0 & 0 & 0 \\
\hline 120-135 & K.GLGTDEDSLIEIICSR.T & 0 & 0 & 0 & 0 \\
\hline 136-145 & R.TNQELQEINR.V & 0 & 0 & 0 & 0 \\
\hline 153-168 & K.TDLEKDIISDTSGDFR.K & 0 & 0 & 0 & 0 \\
\hline 179-196 & $\begin{array}{l}\text { R.RAEDGSVIDYELIDQD } \\
\text { AR.D }\end{array}$ & 0 & 0 & 0 & 0 \\
\hline 197-204 & R.DLYDAGVK.R & 0 & & 0 & \\
\hline 213-220 & K.WISIMTER.S & & & 0 & \\
\hline 221-227 & R.SVPHLQK.V & & & 0 & \\
\hline $232-245$ & R.YKSYSPYDMLESIR.K & 0 & 0 & 1 & \\
\hline $274-281$ & R.LYDSMKGK.G & & & 2 & \\
\hline 296-302 & R.SEVDMLK.I & 0 & & 0 & \\
\hline 314-324 & K.SLYYYIQQDTK.G & 0 & 0 & 0 & 0 \\
\hline
\end{tabular}

\section{Discussion}

Proteomic approaches, based on comparative proteome profiling of cell lines, demonstrate an effective method of identifying candidate proteins implicated in the sensitivity/resistance to therapeutic drugs. 2D-DIGE is now recognized as an extremely robust method in comparative proteomics to analyse and detect changes related to a variety of effects on the cellular proteome.

Dasatinib, a multi-target tyrosine kinase inhibitor, has activity against several kinases including BCR-Abl, SRC kinases, C-Kit, PDGFR, and ephrin-A receptor kinases [6]. In preclinical studies, dasatinib has shown good anti-proliferative and antiinvasive effects in melanoma cell lines [9-11]. However, the preclinical studies in melanoma cell lines have failed to identify alterations in signalling pathways which determine sensitivity or resistance to dasatinib therapy. Because dasatinib inhibits phosphorylation of specific tyrosine kinases, we performed 2D-DIGE proteomic analysis of phospho-enriched samples to provide a global screen of the effects of dasatinib on signalling pathways in a sensitive and resistant model of melanoma.

In this study, phosphoprotein enrichment, 2D-DIGE separation, and mass spectrometry identification were performed to compare and analyse the alterations in abundance of phospho-enriched proteins from an isogenic melanoma 
A
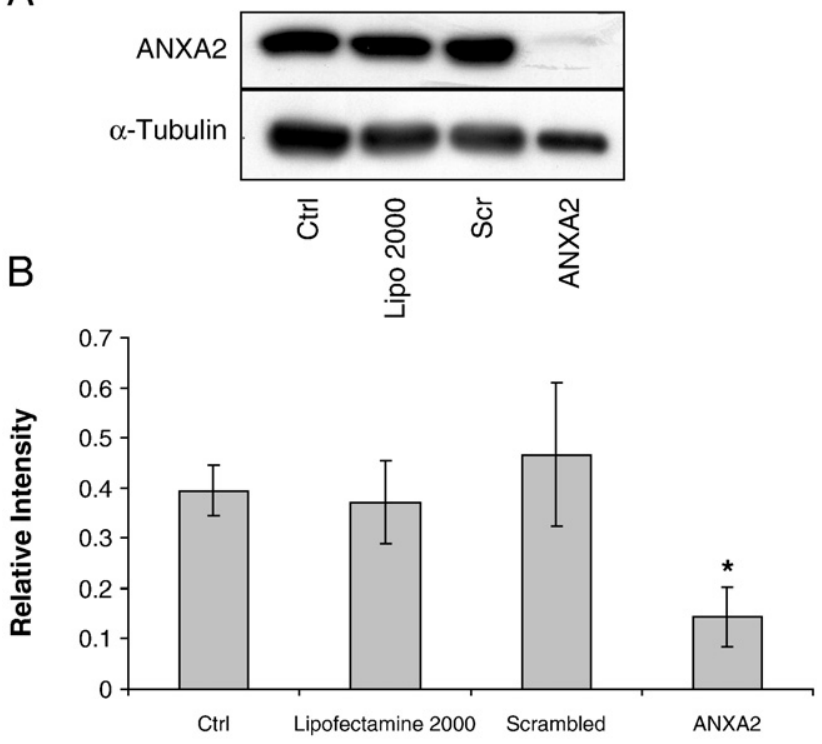

C

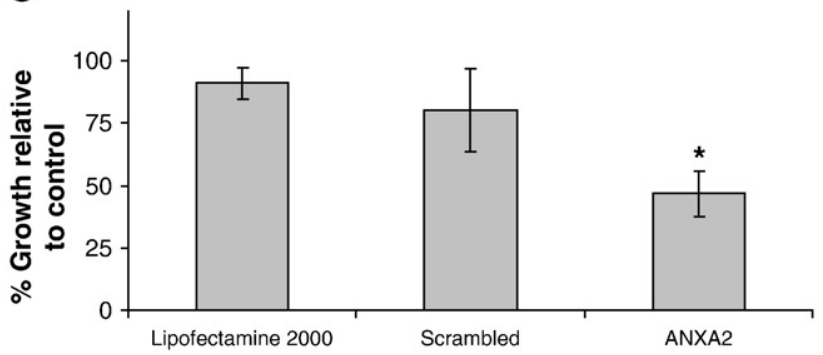

Fig. 6 - (A) Western blot analysis of ANXA2 levels in siRNA treated WM-115 cells. (B) Densitometry analysis of ANXA2 bands (normalized to $\alpha$-tubulin). Error bars represent the standard deviation of triplicate siRNA transfection experiments. *Indicates that $p \leq 0.05$ for ANXA2 siRNA compared to scrambled siRNA. (C) Effect of ANXA2 siRNA on growth in WM-115 melanoma cell line. Error bars represent the standard deviation of triplicate experiments. *Indicates that $\boldsymbol{p} \leq \mathbf{0 . 0 5}$ for ANXA2 siRNA compared to scrambled siRNA.

model following treatment with $100 \mathrm{nM}$ dasatinib. In our laboratory dasatinib has been shown to reduce SRC kinase phosphorylation after 6-hour treatment in several melanoma cell lines [9]. SRC kinase has been previously shown to regulate several key signalling pathways including the PI3/AKT signalling pathway, which has been shown to have control over proliferation and invasion [12]. Therefore, we examined the effects of dasatinib on phosphorylation levels of proteins after 6 hours of treatment with dasatinib as alterations observed may relate to changes associated with SRC kinase inhibition. Differentially regulated phosphoproteins, which could potentially be associated with modulating response to dasatinib, were also identified.

In WM-115 cells, dasatinib treatment reduced the levels of moesin (MSN) and radixin (RDX) phosphoproteins. Moesin and radixin are members of the ezrin, moesin, radixin (ERM) family of molecules involved in the association of actin filaments with the plasma membrane. Moesin is constitutively activated by phosphorylation of threonine 555 [20] and the activation of
A
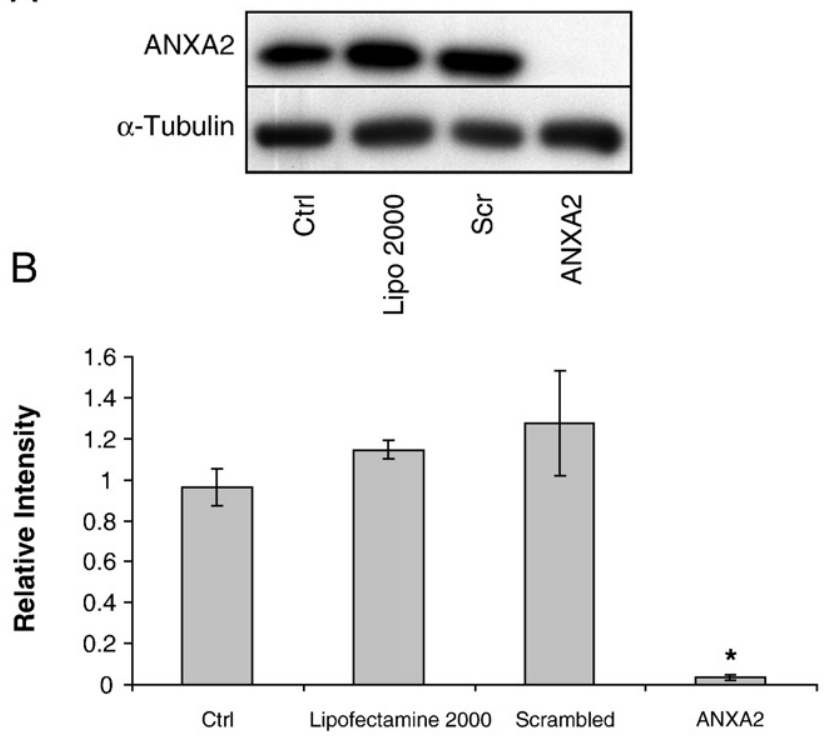

C

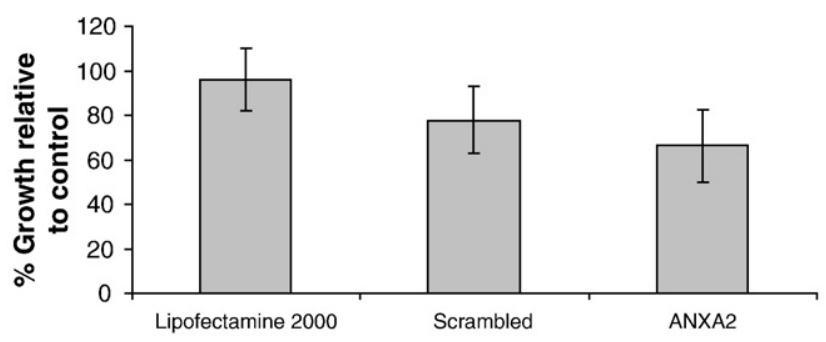

Fig. 7 - (A) Western blot analysis of ANXA2 in siRNA treated WM-266-4 cells. (B) Densitometry analysis of ANXA2 bands (normalized to $\alpha$-tubulin). Error bars represent the standard deviation of triplicate siRNA transfection experiments.

*Indicates that $\boldsymbol{p} \leq \mathbf{0 . 0 5}$ for ANXA2 siRNA compared to scrambled siRNA. (C) Effect of ANXA2 siRNA on growth in WM-266-4 cells. Error bars represent the standard deviation of triplicate experiments. ${ }^{*}$ Indicates that $p \leq 0.05$ for ANXA2 siRNA compared to scrambled siRNA.

ERM family members links actin filaments to CD43, CD44, and ICAM-1 which are involved in adhesion [21]. Moesin is critical for invasion in 3D matrices [22], and phosphorylation of moesin has also been linked with invasion in endometrial cells [23]. The alterations in MSN and RDX, observed in the dasatinib-treated WM-115 cells, may play a role in the effects of dasatinib on migration and invasion.

In the dasatinib-sensitive WM-115 cells, phosphoproteomic analysis suggested that dasatinib treatment increases the level of ANXA2 phosphoproteins, which is not observed in dasatinibresistant WM-266-4 cells. Treatment with dasatinib increased phosphorylation levels of ANXA2 in WM-115 cells but not in WM-266-4 cells, which suggests that phosphorylated ANXA2 may play a role in dasatinib sensitivity. ANXA2 can be phosphorylated on both serine and tyrosine residues. Immunoblotting analysis of phosphotyrosine and phosphoserine suggest that dasatinib increased phosphorylation of tyrosine residues in WM-115 but not in WM-266-4 cells, whilst phosphorylation of serine residues appeared to be reduced by dasatinib treatment in 
both WM-115 and WM-266-4 cells, although the levels of serine phosphorylation detected were very low.

Analysis of the 4 identified ANXA2 isoforms suggested that ANXA2 spot 27 and 29 may differ in the phosphorylation status of the tyrosine (Y) 30 and/or threonine (T) 31 residues. These phosphorylation events were not identified in either ANXA2 spot 26 or 30 . ANXA2 Y30 has been previously identified by mass spectrometry but no functional role has been identified for this residue (www.phosphosite.org). Phosphorylation of threonine 31 has not been previously reported (www.phosphosite.org).

ANXA2 spot 28 may be phosphorylated at Y232, Y235, or Y238 or at serine (S) residues 234, S236, or S243. No phosphorylation events were identified in this region of the protein (232245 ) in either spot 26 or 27; however, this peptide sequence was not detected in the analysis of spot 29. Phosphory- lation of Y236 has been previously associated with migration [24]. The exact site of the phosphorylation was not established during our analysis. Two potential phosphorylation events were also detected on ANXA2 spot 28, on residues Y275 and S277. Phosphorylation of Y275 has previously been found to be altered in SRC transformed mice [25]. However, this peptide sequence (274-281) was not detected in the other three ANXA2 isoforms so it is unclear whether these phosphorylation events are specific to this isoform.

Spot 26 may be unphosphorylated or may have other potential phosphorylation sites that were not detected in the mass spectrometry analysis due to limited peptide coverage.

Phosphorylation of ANXA2 at Y23 is implicated in the control of cancer cell motility. SRC kinase can directly phosphorylate ANXA2 on Y23 [26,27], which may negatively modulate ANXA2 function and inhibit the ability of ANXA2 to bind F-actin [27]. However, another study showed that phosphorylation of ANXA2 Y23 is essential for ANXA2 function and its association with the endosome [19]. In our analysis of phosphorylation events in the four ANXA2 isoforms detected, no phosphorylation events were detected at Y23.

Dasatinib, an SRC kinase inhibitor, has been shown to inhibit the phosphorylation of SRC kinase at its active site Y418 and should thus decrease phosphorylation of ANXA2 at Y23. However, we did not detect phosphorylation of Y23 on the four ANXA2 isoforms identified.

Contrary to the anticipated decrease in phosphorylation, we observed increases in the abundance of three ANXA2 isoforms which are phosphorylated at alternative sites. The alterations in signalling pathways resulting from dasatinib inhibition of its targets have yet to be elucidated. However, these changes may result in increases in ANXA2 phosphorylation at several uncharacterised sites.

Annexin-2 (ANXA2) is a substrate for PKC, PDGFR, and SRC kinase and acts in a calcium-dependent manner to interact with the cell surface and affect the movement of phospholipids [28]. It is linked with invasion, metastasis, and angiogenesis in cancer [28]. ANXA2 is usually found in a tetrameric construct consisting of two ANXA2 chains and two S100A10 chains. The ANXA2-S100A10 complex has a channel modulating effect on the cell surface which can affect the membrane interactions of lipids [29]. SRC kinase has been shown to phosphorlyate both ANXA2 [26,27] and S100A10 [30].
Expression of ANXA2 is increased in glioma, pancreatic, and colorectal cancer, whilst its expression was reduced in prostate cancer [28]. Lower levels of ANXA2 were detected in metastatic lung tumours compared to primary lung tumours [28]. In our study, lower levels of phosphorylated ANXA2 were detected in the metastatic cell line, WM-266-4, compared to the primary cell line, WM-115. Further analysis of ANXA2 phosphorylation in primary and metastatic melanoma tumour samples would be required to determine if loss of ANXA2 phosphorylation is associated with melanoma progression.

ANXA2 siRNA treatment has previously been shown to reduce proliferation and migration and to increase apoptosis in a range of cancer cell types [31-35]. We found that ANXA2 siRNA caused significant inhibition of growth in the dasatinibsensitive WM-115 cells. In the dasatinib-resistant WM-266-4 cells a slight decrease in growth was observed with the ANXA2 siRNA treatment but the effect was not significant when compared to treatment with a scrambled siRNA. These results suggest that ANXA2 may play a role in regulating proliferation in WM-115 cells but this regulation is lost or reduced in WM-266-4 cells. Further investigation will be required to elucidate the role of ANXA2 in response to dasatinib treatment and to determine if ANXA2 could be used as a predictive or pharmacodynamic biomarker for dasatinib treatment in melanoma patients.

Our study found that 2D-DIGE analysis was an effective method to identify proteins with altered phosphorylation that may play a role in sensitivity and resistance to dasatinib in an isogenic model of sensitivity in melanoma. Several isoforms of ANXA2 were altered by dasatinib treatment and siRNA knockdown of ANXA2 resulted in significant proliferation inhibition in the dasatinib-sensitive cell line WM-115 whilst there was only a slight decrease in proliferation in dasatinibresistant WM-266-4 cells. Therefore, ANXA2 may play a role in modulating response to dasatinib in melanoma.

\section{Acknowledgments}

This research was supported by the Cancer Clinical Research Trust and the Targeted Research Initiatives Fund, Faculty of Science and Health, Dublin City University.

\section{R E F E R E N C E S}

[1] Gray-Schopfer V, Wellbrock C, Marais R. Melanoma biology and new targeted therapy. Nature 2007;445:851-7.

[2] Perlis C, Herlyn M. Recent advances in melanoma biology. Oncologist 2004;9:182-7.

[3] Garbe C, Leiter U. Melanoma epidemiology and trends. Clin Dermatol 2009;27:3-9.

[4] Mitchell MS. Chemotherapy for melanoma: the resultant of conflicting vectors. J Clin Oncol 2004;22:2043-5.

[5] Becker JC, Kampgen E, Brocker E. Classical chemotherapy for metastatic melanoma. Clin Exp Dermatol 2000;25:503-8.

[6] Lombardo LJ, Lee FY, Chen P, Norris D, Barrish JC, Behnia K, et al. Discovery of N-(2-chloro-6-methyl-phenyl)-2-(6-(4-(2hydroxyethyl)- piperazin-1-yl)-2-methylpyrimidin-4-ylamino) thiazole-5-carboxamide (BMS-354825), a dual Src/Abl kinase inhibitor with potent antitumor activity in preclinical assays. J Med Chem 2004;47:6658-61. 
[7] Finn RS, Dering J, Ginther C, Wilson CA, Glaspy P, Tchekmedyian $\mathrm{N}$, et al. Dasatinib, an orally active small molecule inhibitor of both the src and abl kinases, selectively inhibits growth of basal-type/ "triple-negative" breast cancer cell lines growing in vitro. Breast Cancer Res Treat 2007;105: 319-26.

[8] Serrels A, Macpherson IR, Evans TR, Lee FY, Clark EA, Sansom OJ, et al. Identification of potential biomarkers for measuring inhibition of Src kinase activity in colon cancer cells following treatment with dasatinib. Mol Cancer Ther 2006;5:3014-22.

[9] Eustace AJ, Crown J, Clynes M, O’Donovan N. Preclinical evaluation of dasatinib, a potent Src kinase inhibitor, in melanoma cell lines. J Transl Med 2008;6:53.

[10] Homsi J, Cubitt CL, Zhang S, Munster PN, Yu H, Sullivan DM, et al. Src activation in melanoma and Src inhibitors as therapeutic agents in melanoma. Melanoma Res 2009;19: 167-75.

[11] Buettner R, Mesa T, Vultur A, Lee F, Jove R. Inhibition of Src family kinases with dasatinib blocks migration and invasion of human melanoma cells. Mol Cancer Res 2008;6:1766-74.

[12] Homsi J, Cubitt C, Daud A. The Src signaling pathway: a potential target in melanoma and other malignancies. Expert Opin Ther Targets 2007;11:91-100.

[13] Hong Z, Zhang QY, Liu J, Wang ZQ Zhang Y, Xiao Q, et al. Phosphoproteome study reveals Hsp27 as a novel signaling molecule involved in GDNF-induced neurite outgrowth. J Proteome Res 2009;8:2768-87.

[14] Tang W, Deng Z, Oses-Prieto JA, Suzuki N, Zhu S, Zhang X, et al. Proteomics studies of brassinosteroid signal transduction using prefractionation and two-dimensional DIGE. Mol Cell Proteomics 2008;7:728-38.

[15] Westermark B, Johnsson A, Paulsson Y, Betsholtz C, Heldin CH, Herlyn M, et al. Human melanoma cell lines of primary and metastatic origin express the genes encoding the chains of platelet-derived growth factor (PDGF) and produce a PDGF-like growth factor. Proc Natl Acad Sci USA 1986;83:7197-200.

[16] Karp NA, Lilley KS. Maximising sensitivity for detecting changes in protein expression: experimental design using minimal CyDyes. Proteomics 2005;5:3105-15.

[17] Alban A, David SO, Bjorkesten L, Andersson C, Sloge E, Lewis $S$, et al. A novel experimental design for comparative two-dimensional gel analysis: two-dimensional difference gel electrophoresis incorporating a pooled internal standard. Proteomics 2003;3:36-44.

[18] Perez-Perez R, Ortega-Delgado FJ, Garcia-Santos E, Lopez JA, Camafeita E, Ricart W, et al. Differential proteomics of omental and subcutaneous adipose tissue reflects their unalike biochemical and metabolic properties. J Proteome Res 2009;8:1682-93.

[19] Morel E, Gruenberg J. Annexin A2 binding to endosomes and functions in endosomal transport are regulated by tyrosine 23 phosphorylation. J Biol Chem 2009;284:1604-11.

[20] Niggli V, Rossy J. Ezrin/radixin/moesin: versatile controllers of signaling molecules and of the cortical cytoskeleton. Int J Biochem Cell Biol 2008;40:344-9.
[21] Hoeflich KP, Tsukita S, Hicks L, Kay CM, Tsukita S, Ikura M. Insights into a single rod-like helix in activated radixin required for membrane-cytoskeletal cross-linking. Biochemistry 2003;42:11634-41.

[22] Estecha A, Sanchez-Martin L, Puig-Kroger A, Bartolome RA, Teixido J, Samaniego R, et al. Moesin orchestrates cortical polarity of melanoma tumour cells to initiate 3D invasion. J Cell Sci 2009;122:3492-501.

[23] Flamini MI, Sanchez AM, Goglia L, Tosi V, Genazzani AR, Simoncini T. Differential actions of estrogen and SERMs in regulation of the actin cytoskeleton of endometrial cells. Mol Hum Reprod 2009;15:675-85.

[24] Wolf-Yadlin A, Kumar N, Zhang Y, Hautaniemi S, Zaman M, Kim HD, et al. Effects of HER2 overexpression on cell signaling networks governing proliferation and migration. Mol Syst Biol 2006;2:54.

[25] Luo W, Slebos RJ, Hill S, Li M, Brabek J, Amanchy R, et al. Global impact of oncogenic Src on a phosphotyrosine proteome. J Proteome Res 2008;7:3447-60.

[26] Deora AB, Kreitzer G, Jacovina AT, Hajjar KA. An annexin 2 phosphorylation switch mediates p11-dependent translocation of annexin 2 to the cell surface. J Biol Chem 2004;279:43411-8.

[27] Hubaishy I, Jones PG, Bjorge J, Bellagamba C, Fitzpatrick S, Fujita DJ, et al. Modulation of annexin II tetramer by tyrosine phosphorylation. Biochemistry 1995;34:14527-34.

[28] Mussunoor S, Murray GI. The role of annexins in tumour development and progression. J Pathol 2008;216:131-40.

[29] Monastyrskaya K, Tschumi F, Babiychuk EB, Stroka D, Draeger A. Annexins sense changes in intracellular $\mathrm{pH}$ during hypoxia. Biochem J 2008;409:65-75.

[30] Powell MA, Glenney JR. Regulation of calpactin I phospholipid binding by calpactin I light-chain binding and phosphorylation by p60v-src. Biochem J 1987;247:321-8.

[31] Rhodes N, Heerding DA, Duckett DR, Eberwein DJ, Knick VB, Lansing TJ, et al. Characterization of an Akt kinase inhibitor with potent pharmacodynamic and antitumor activity. Cancer Res 2008;68:2366-74.

[32] Tatenhorst L, Rescher U, Gerke V, Paulus W. Knockdown of annexin 2 decreases migration of human glioma cells in vitro. Neuropathol Appl Neurobiol 2006;32:271-7.

[33] Bao H, Jiang M, Zhu M, Sheng F, Ruan J, Ruan C. Overexpression of Annexin II affects the proliferation, apoptosis, invasion and production of proangiogenic factors in multiple myeloma. Int J Hematol 2009;90:177-85.

[34] Chiang Y, Rizzino A, Sibenaller ZA, Wold MS, Vishwanatha JK. Specific down-regulation of annexin II expression in human cells interferes with cell proliferation. Mol Cell Biochem 1999;199:139-47.

[35] Huang Y, Jin Y, Yan CH, Yu Y, Bai J, Chen F, et al. Involvement of Annexin A2 in p53 induced apoptosis in lung cancer. Mol Cell Biochem 2008;309:117-23. 